\title{
Novel nonsense variants in SLURP1 and DSG1 cause palmoplantar keratoderma in Pakistani families
}

\author{
Abida Akbar ${ }^{1,2}$, Claire Prince ${ }^{2}$, Chloe Payne 2 , James Fasham², Wasim Ahmad³, Emma L. Baple ${ }^{2}$, Andrew H. Crosby ${ }^{2}$, \\ Gaurav V. Harlalka ${ }^{2,4}$ and Asma Gul ${ }^{1 *}$ (D)
}

\begin{abstract}
Background: Inherited palmoplantar keratodermas (PPKs) are clinically and genetically heterogeneous and phenotypically diverse group of genodermatoses characterized by hyperkeratosis of the palms and soles. More than 20 genes have been reported to be associated with PPKs including desmoglein 1 (DSG1) a key molecular component for epidermal adhesion and differentiation. Mal de Meleda (MDM) is a rare inherited autosomal recessive genodermatosis characterized by transgrediens PPK, associated with mutations in the secreted LY6/ PLAUR domain containing 1 (SLURP1) gene.
\end{abstract}

Methods: This study describes clinical as well as genetic whole exome sequencing (WES) and di-deoxy sequencing investigations in two Pakistani families with a total of 12 individuals affected by PPK.

Results: WES identified a novel homozygous nonsense variant in SLURPI, and a novel heterozygous nonsense variant in DSG1, as likely causes of the conditions in each family.

Conclusions: This study expands knowledge regarding the molecular basis of PPK, providing important information to aid clinical management in families with PPK from Pakistan.

Keywords: Mal de Meleda, Palmoplantar keratoderma, SLURP1, DSG1, Mutation, Variant, Exome sequencing

\section{Background}

Palmoplantar keratoderma (PPK) is a heterogeneous entity of both genetics and acquired keratinization disorder, which is characterized by persistent marked epidermal thickening of palms and soles [1]. Hereditary PPKs comprising an increasing number of entities with different prognoses, which may be associate with cutaneous and extracutaneous manifestations [2].

Depending on different patterns of hyperkeratosis, PPKs are further classified into four distinct types: diffuse, striate, focal and punctate [3, 4]. So far, deleterious mutations in $>20$ genes have been reported in pathogenesis of different forms of hereditary PPKs [3, 4]. In last few years, advent of cutting edge genetic techniques such as whole genome microarray scans and whole exome sequencing

\footnotetext{
* Correspondence: gulasma@iiu.edu.pk

${ }^{1}$ Department of Biological Sciences, International Islamic University, $\mathrm{H}-10$, Islamabad 44000, Pakistan

Full list of author information is available at the end of the article
}

have incredibly accelerated the identification of disease causing variants in many genes involved in various inherited forms of PPKs, and thus significantly increasing understanding about intricate molecular mechanisms of heterogeneous disorders, consecutively aiding valuable genetic counselling and patient care [3].

Mal de Meleda (MDM), a type of transgradient palmoplantar keratoderma (PPK), is a rare autosomal recessive disorder. Luca Stulli, a Croatian born scientist in 1826 first described Mal de Meleda on the Adriatic Meleda island (now Mljet) [5]. The disease can feature other potentially disfiguring effects on the hands and feet that can severely impact function.

The disease onset is soon after birth and is clinically characterized by erythema, transgradients and progradients hyperkeratosis of palms and soles with well demarcated borders and hypohydrosis. Other associated features are brachydactyly, nail abnormalities and lichenoid plaques [6]. Rigorous keratoderma can lead to deformity in 
hands and feet and gradually this may results into severe impairment $[7,8]$.

Furthermore, previous reports have shown that MDM may be caused due to mutations in the SLURP1 gene (previously known as ARS-B gene) encoding a secreted toxin-like mammalian lymphocyte antigen 6/urokinasetype plasminogen activator receptor-related protein 1(SLURP1). Expression of SLURP1 is reported in epithelium, stomach, sensory nerve cells, gums, esophagus and immune cells with highest level in keratinocytes especially in palms and soles [9-11].

Striate PPK type I is a rare type of PPK and shows the autosomal dominant mode of inheritance associated with DGS1 heterozygous mutation. Clinical features of this condition are linear hyperkeratotic lesions on the palms extending along the length of fingers and associated with thick patches of diffuse hyperkeratosis on the soles [12].

Heterozygous mutation in DSG1 gene in an autosomal dominant pattern have also been reported in focal PPK in a Libyan family, and in a Jewish Yemenite family with diffuse PPK $[13,14]$, a discovery which elucidates that different patterns of palmoplantar involvement may result from mutations in the DSG1 gene. Additionally, biallelic mutations in DSG1 gene have also been recently reported in the severe SAM syndrome, characterized by sinusitis, palmoplantar keratoderma, erythroderma, multiple allergies and metabolic defects, with heterozygous mutation carriers only presenting hyperkeratotic palmoplantar lesions [15].

Here we report findings regarding investigations of two families from Pakistan with clinically-defined PPK, for which the specific genetic basis was unclear.

\section{Methods}

\section{Genetic studies}

The research work presented in this manuscript was approved by the Ethical Review Boards Committee at International Islamic University, Islamabad, Pakistan (IIUI; Pakistan). Informed written consent was obtained for all participants for the collection of blood samples, with clinical evaluations and family histories performed by a dermatologist. Extraction of high quality genomic DNA from the whole blood was carried out by using the ReliaPrep ${ }^{\text {Tw }}$ kit (Blood gDNA Miniprep System, Promega) following the manufacturer's protocol. Whole exome sequencing (WES) was undertaken on a NextSeq500 (Illumina, CA, San Diego, USA) with targeting using Agilent Sure select Whole Exome v6. The reads were aligned using BWA-MEM (v0.7.12), with mate-pairs fixed and duplicates removed using Picard (v1.129). InDel realignment and base quality recalibration were performed using GATK (v3.4-46). SNVs and InDels were detected using GATK Haplotype Caller or SnpEff tool (http://snpeff.sourceforge.net/SnpEff_manual. html), and annotated using Alamut batch (v1.4.4). Read depth was determined for the whole exome using GATK Depth of Coverage.

Primer3 web software was used to design the allele-specific primers (primer sequences are available upon request) to validate and verify the segregation of identified variants via Sanger sequencing. Polymerase chain reaction (PCR) was performed for all affected and healthy individuals of recruited families by using allele-specific primers following standard conditions, with products sequenced by Source Bio-Science Life Sciences (https://www.sourcebioscience.com/).

\section{Results}

\section{Subjects}

Pedigree analysis was indicative of an autosomal recessive inheritance pattern of family 1 , and an autosomal dominant mode of inheritance of family 2 (Fig. 1). All 12 living affected individuals with PPK as well as 6 unaffected (healthy) individuals including parents and siblings from both families (Family 1 and 2) were investigated. The seven affected individuals from family 1:IV:7, IV:8, IV:12, V:2, V:4, V:8 and V:9 were 27, 22, 45, $16,11,15$ and 13 years of age respectively at the time of examination, while the five affected individuals from family 2: III:2, III:5, III:6, IV:1 and IV:2 were 28, 36, 40, 12 and 8 years of age respectively. On the basis of basic clinical dermatological examination, PPK was the main finding exhibit in all patients (affected members) of the recruited families.

Disease onset was from 3 months to 1 year. Affected individuals of family 1 show cuff-like pattern with well demarcated margins and waxy yellow tone on hands and feet. Diffuse hyperkeratosis of hand and feet was common in patients. Fingers were tapered towards the tips and flexion deformity due to contractures was observed in 2 (IV:7 and IV:8) patients. Knuckle pads were observed in interphalangeal joints and hyperhidrosis was also common in all patients. Patients in family 2 showed diffuse hyperkeratosis with cracks and fissuring of the volar surface of the digits of hands and soles, toes were observed in two siblings. All other patients have mild hyperkeratosis. Mild to severe deafness was observed in patients and one patient (III:5) was deaf as well as mute. Both families' phenotypes are summarized in Table 1 and Fig. 1.

All patients of family 1 and 2 were intellectually normal and hair, nail, teeth and cardiac anomalies were not observed in any of the patient. Disease conditions worsened due to aging.

\section{Genetic findings}

To identify the causative gene mutation, single affected individual from each of the family was initially selected 


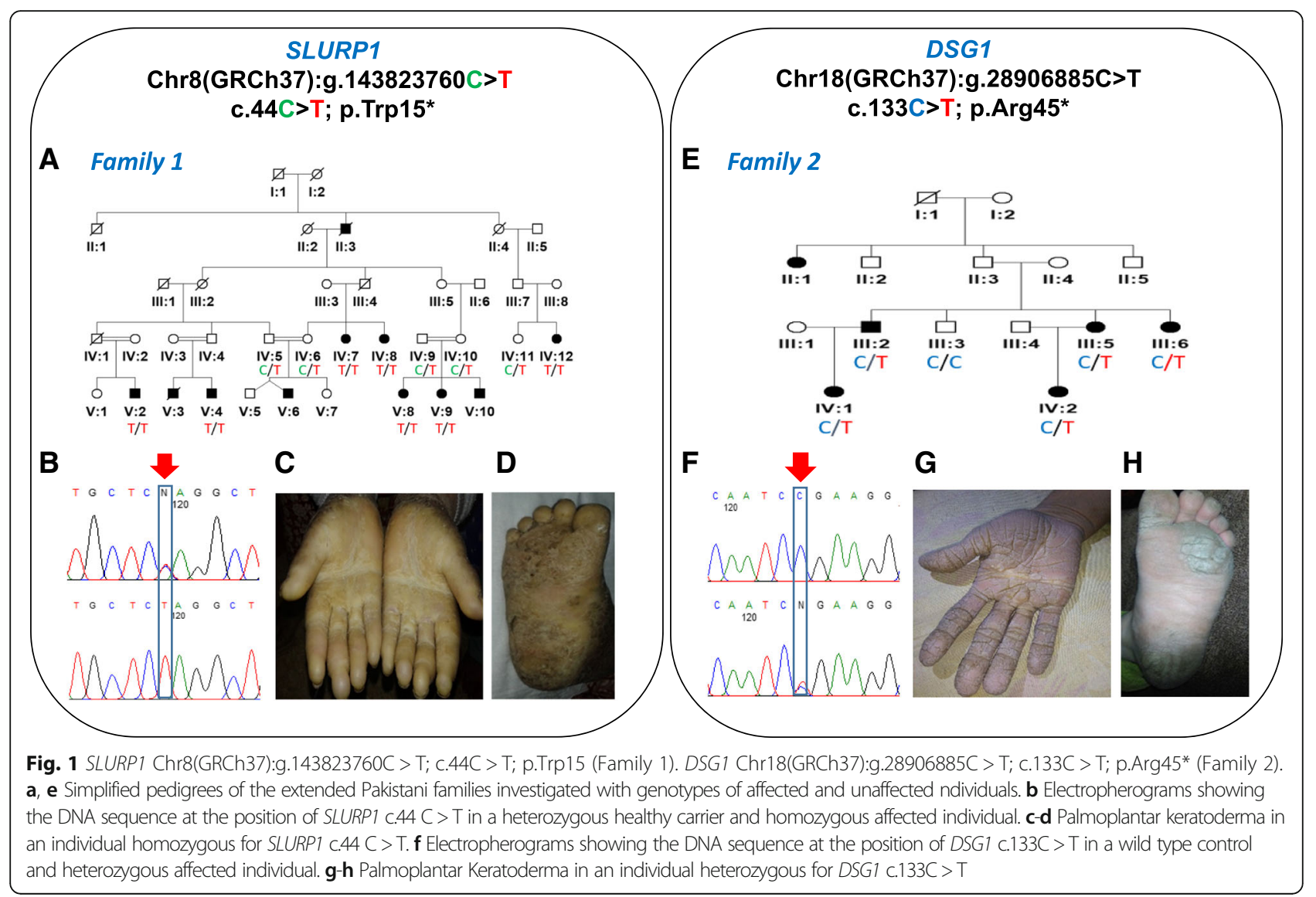

to perform WES (subject IV:12 of family 1 and III:2 of family 2, Fig. 1) to generate a profile of rare and novel sequence variants, with regard to mode of inheritance in each of the families. After that, exome data was first reviewed to identify pathogenic variants in disease associated genes, filtering for highly likely deleterious (nonsense, frame-shift, non-synonymous exonic or splicesite) variants for comparison with allele frequencies in online genome databases (including the Exome Aggregation Consortium; ExAC, the 1000 Genomes Project and the Genome Aggregation Database; gnomAD). This identified a single candidate novel homozygous nonsense variant [NM_020427.2:c.44G > A; Chr8:143823760C > T (GRCh37)] in the first coding exon of SLURP1 gene (Fig. 1 ) in family 1 . This variant leads to substitution of tryptophan by a premature termination codon and is at the evolutionary conserved position 15 (p.Trp15\%). In family 2, a heterozygous variant [NM_001942.3:c.133C > T; Chr18:28906885C > T (GRCh37)] was identified in coding exon 3 of the DSG1 gene (Fig. 1), which is predicted to result in a premature stop codon (p.Arg45\%). The SLURP1 gene variant in family 1 is not listed in online genome databases and segregates as predicted for an autosomal recessive form in family 1 . The DSG1 gene variant identified of family 2 is listed in the gnomAD browser database in 1 Latino individual in heterozygous form out of 31,370 genomes, corresponding to a minor allele frequency of 0.00003188 ; both variants are summarized in Additional file 1: Tables S1 and S2 alongside all other reported disease-associated SLURP1 and DSG1 variants.

\section{Discussion}

SLURP1 has been localized to the granular layer of epidermis [16], where it functions as part of nicotinic acetylcholine receptors found on keratinocyte cells as a pro-apoptotic protein [17]. Arredondo et al. [17] demonstrated that keratinocytes are stimulated by SLURP1 through nicotinic acetylcholine receptor, leading to decline in keratinocytes cell number, indicative of the inhibitory and regulatory nature of SLURP1. Therefore, when SLURP1 is non-functional, as seen in Mal de Meleda, severe hyperkeratosis results due to improper keratinocyte apoptosis regulation $[8,18]$.

We identified nonsense variant in family 1 which causes substitution of evolutionarily conserved tryptophan at 15th amino acid position in SLURP1 by a premature termination codon. Nonsense variant (c.129C > A; p.Cys43*) is also reported in exon 2 of SLURP1 gene in a Turkish 
Table 1 Clinical phenotypes of study participants of family 1 and 2

\begin{tabular}{|c|c|c|c|c|c|c|c|c|c|c|c|c|}
\hline \multirow[b]{2}{*}{ Individuals } & \multicolumn{7}{|l|}{ Family 1} & \multicolumn{5}{|l|}{ Family 2} \\
\hline & $\mathrm{IV}: 7$ & $\mathrm{IV}: 8$ & $\mathrm{IV}: 12$ & $\mathrm{~V}: 2$ & $V: 4$ & $\mathrm{~V}: 8$ & $\vee: 9$ & \|\|$: 2$ & |ll:5 & III:6 & $\mathrm{IV}: 1$ & $\mathrm{IV}: 2$ \\
\hline Age & 27 years & 22 years & 45 Years & 16 years & 11 years & 15 years & 13 years & 28 years & 36 years & 40 years & 12 years & 8 years \\
\hline Sex & $\mathrm{F}$ & $\mathrm{F}$ & $\mathrm{F}$ & M & M & $\mathrm{F}$ & $\mathrm{F}$ & M & $\mathrm{F}$ & $\mathrm{F}$ & $\mathrm{F}$ & $\mathrm{F}$ \\
\hline Disease onset & 1 year & 1 year & 6 months & 6 months & 1 year & 3 months & 6 months & By birth & By birth & By birth & By birth & $\begin{array}{l}\text { By } \\
\text { birth }\end{array}$ \\
\hline Inheritance & \multicolumn{7}{|c|}{ Autosomal Recessive } & \multicolumn{5}{|c|}{ Autosomal Dominant } \\
\hline Diffuse PPK & + & + & + & + & + & + & + & + & + & + & + & + \\
\hline Scale colour & Yellowish & Yellowish & Yellowish & Yellowish & Yellowish & Yellowish & Yellowish & - & - & - & - & - \\
\hline Cuff like margins & ++ & ++ & ++ & ++ & ++ & ++ & ++ & - & - & - & - & - \\
\hline Pseudoainhum & - & - & - & - & - & - & - & - & - & - & - & - \\
\hline $\begin{array}{l}\text { Cracked } \\
\text { Hypekeratosis }\end{array}$ & - & - & - & - & - & - & - & ++ & +++ & + & + & + \\
\hline Deafness & - & - & - & - & - & - & - & Mild & Complete & Mild & Mild & Mild \\
\hline Speech abnormality & - & - & - & - & - & - & - & Mild & Complete & - & - & - \\
\hline $\begin{array}{l}\text { Diffuse } \\
\text { hyperkeratosis }\end{array}$ & - & - & - & - & - & - & - & Severe & Severe & Mild & Mild & Mild \\
\hline $\begin{array}{l}\text { Teeth, hairs and } \\
\text { nails }\end{array}$ & Normal & Normal & Normal & Normal & Normal & Normal & Normal & Normal & Normal & Normal & Normal & Normal \\
\hline Finger deformity & - & ++ & ++ & + & - & - & - & - & + & + & - & - \\
\hline Hyperhidrosis & + & + & + & + & + & + & + & - & - & - & - & - \\
\hline Cardiomyopathy & - & - & - & - & - & - & - & - & - & - & - & - \\
\hline
\end{tabular}

$+=$ presence of feature, - -absence of feature, $+++=$ present in severe form

family. Similarly another nonsense mutation (c.286C $>$ T; p.Arg96*) is also found in exon 3 in Croatian family and is predicted to truncate protein synthesis via nonsense-mediated mRNA decay $[19,20]$. Family reported in this study have same clinical features to previously reported Mal de Meleda families.

The SLURP1 gene mutation p.Gly86Arg is most often found in sporadic patients with MDM of Asian origin [21, 22].

So far 20 mutations in SLURP1 are reported to cause Mal de Meleda, a form of PPK (Additional file 1: Table S1,). c.44G > A; p.Trp15Term is the second variant identified in Pakistan apart from c. $2 \mathrm{~T}>\mathrm{C}$, p.Met1Thr variant which was recently reported [23].

"Desmoglein" comprises of the two Greek words "desmos" for "tie" and "glein" for "glue-like." Perturbations of desmoglein expression in the epidermis have been known to impact cell adhesion properties. DSG1 is distinctively located, just above the stratum germinativum, to be candidate of epidermis stratification and differentiation [24]. A study in which DSG1 was down regulated in skin culture confirmed the importance of DSG1 for directing those functions [25].

In all reported PPKs cases where DSG1 gene variants (frameshift or nonsense) have been reported, there is evidence that affected protein haploinsufficiency leads to the striate, focal PPK and striate PPK with wooly hair and cardiomyopathy. Haploinsufficiency is predicted to cause through nonsense mediated mRNA decay because of premature termination codons [26, 27]. Interestingly, a heterozygous DSG1 mutation has also been reported in focal PPK [13].

To date, 31 mutations (8 nonsense mutations, 14 frame-shift variants and 9 splice-site variants) in DSG1 have been reported to cause striate/focal PPK (Additional file 1: Table S2). In 2009, Dua-Awereh et al. reported five heterozygous variants (p.Arg26*; c.373-2A > G; c.515C > T; c.1266-3C > G and c.1399delA) in DSG1 gene in five families with autosomal dominant striate PPK [28]. Thus, c.133C > T; p.Arg45* variant identified in this study is the sixth mutation underlying dominantly inherited form of striate PPK in Pakistan.

MDM presented a consistently severe phenotype than Nagashima form of PPK. MDM shows progressive hyperkeratosis among all PPKs and causes flexion contracture and constricting band [29]. While, Nagashima PPK is characterized by non-progressive and mild hyperkeratosis and does not show flexion contracture and constricting band [30, 31]. Nagashima PPK is caused by biallelic loss of function mutation in SERPINB7 while, MDM is caused by SLURP1 gene mutation [20]. Therefore, MDM is genetically distinct from Nagashima PPK [32]. PPKs are diagnosed on the basis of differential diagnosis to find out the 
Table 2 Differential diagnosis of PPKs

\begin{tabular}{|c|c|c|c|c|}
\hline Name & $\begin{array}{l}\text { Disease } \\
\text { Type }\end{array}$ & Clinical Features & Histopathology & Gene \\
\hline $\begin{array}{l}\text { Mal de } \\
\text { Meleda }\end{array}$ & $\begin{array}{l}\text { Diffuse } \\
\text { PPK }\end{array}$ & $\begin{array}{l}\text { 1. Soon after birth } \\
\text { 2.Severe diffuse yellow and waxy thick hyperkeratosis } \\
\text { in a 'glove-and-socks' distribution } \\
\text { 3.Sharp demarcation } \\
\text { 4. Autosomal Recessive }\end{array}$ & $\begin{array}{l}\text { 1.Nonepidermolytic pattern } \\
\text { 2.Increased stratum lucidum } \\
\text { 3.Prominent perivascular inflammatory infiltrate }\end{array}$ & SLURP1 \\
\hline Unna-Thost & & $\begin{array}{l}\text { 1.Soon after birth to early childhood } \\
\text { 2.Diffuse yellowish thick hyperkeratosis with sharp } \\
\text { demarcation at the volar border } \\
\text { 3. Autosomal Dominant }\end{array}$ & $\begin{array}{l}\text { 1.Epidermolytic pattern } \\
\text { (perinuclear vacuolization and granular degeneration of } \\
\text { keratinocytes in the spinous and granular layer) }\end{array}$ & $\begin{array}{l}\text { KRT1, } \\
\text { KRT9 }\end{array}$ \\
\hline $\begin{array}{l}\text { Greither } \\
\text { Disease }\end{array}$ & & $\begin{array}{l}\text { 1.Soon after birth to childhood/adolescence } \\
\text { 2. Diffuse red/yellow moderate to severe } \\
\text { hyperkeratosis } \\
\text { 3. Autosomal Dominant }\end{array}$ & 1.Epidermolytic pattern & KRT1 \\
\hline $\begin{array}{l}\text { Nagashima } \\
\text { PPK }\end{array}$ & & $\begin{array}{l}\text { 1.Mostly within infancy } \\
\text { 2. Diffuse mild reddish hyperkeratosis, red rim; white } \\
\text { spongy appearance after water exposure } \\
\text { 3. Autosomal Dominant }\end{array}$ & 1.Nonepidermolytic pattern & SERPINB7 \\
\hline \multicolumn{5}{|l|}{ Striate PPK } \\
\hline $\begin{array}{l}\text { Striate Type } \\
\text { I PPK }\end{array}$ & $\begin{array}{l}\text { Focal } \\
\text { PPK }\end{array}$ & $\begin{array}{l}\text { 1.Childhood to adolescence } \\
\text { 2. Linear hyperkeratotic distribution on palms and } \\
\text { palmar surface of the fingers } \\
\text { 2.Focal hyperkeratosis at trauma-prone sites on soles } \\
\text { 3.Autosomal Dominant }\end{array}$ & $\begin{array}{l}\text { 1. Hyperkeratosis } \\
\text { 2. Widening of intercellular spaces in the spinous and } \\
\text { granular layer }\end{array}$ & DSG1 \\
\hline $\begin{array}{l}\text { Striate Type } \\
\text { II PPK }\end{array}$ & & $\begin{array}{l}\text { 1.Childhood to early adulthood } \\
\text { 2. Linear hyperkeratotic distribution on palms and } \\
\text { palmar aspect of fingers } \\
\text { 3.Focal hyperkeratosis at trauma-prone sites on soles } \\
\text { 4. Autosomal Dominant }\end{array}$ & $\begin{array}{l}\text { 1. Hyperkeratosis } \\
\text { 2.Widening of intercellular paces and } \\
\text { condensation of the keratin filament network in } \\
\text { suprabasal cell layers }\end{array}$ & DSP \\
\hline \multicolumn{5}{|l|}{ Punctate PPK } \\
\hline $\begin{array}{l}\text { Punctate } \\
\text { PPK Type IA }\end{array}$ & $\begin{array}{l}\text { Focal } \\
\text { PPK }\end{array}$ & $\begin{array}{l}\text { 1.Late childhood to adulthood } \\
\text { 2.Multiple hyperkeratotic papules with central } \\
\text { indentation } \\
\text { 3.Worsening of papules upon exposure to water } \\
\text { 4. Autosomal Dominant }\end{array}$ & $\begin{array}{l}\text { 1. Hyperkeratosis and hypergranulosis } \\
\text { with central epidermal depression }\end{array}$ & $A A G A B$ \\
\hline $\begin{array}{l}\text { Punctate } \\
\text { PPK Type IB }\end{array}$ & & $\begin{array}{l}\text { 1.Late childhood to adulthood } \\
\text { 2.Multiple hyperkeratotic papules with central } \\
\text { indentation } \\
\text { 3. Autosomal Dominant }\end{array}$ & $\begin{array}{l}\text { 1.Hyperkeratosis and hypergranulosis } \\
\text { with central epidermal depression }\end{array}$ & COL14A1 \\
\hline $\begin{array}{l}\text { Punctate } \\
\text { PPK Type ॥ }\end{array}$ & & $\begin{array}{l}\text { 1.Puberty to early adulthood } \\
\text { 2.Multiple spiny keratosispits with keratotic plugs (late } \\
\text { onset) } \\
\text { 4. Autosomal Dominant }\end{array}$ & $\begin{array}{l}\text { 1. Columns of parakeratotic corneocytes (cornoid } \\
\text { lamellae) } \\
\text { 2.Superficial epidermal depression where the granular } \\
\text { layer is reduced or absent }\end{array}$ & Unknown \\
\hline $\begin{array}{l}\text { Punctate } \\
\text { PPK Type III }\end{array}$ & & $\begin{array}{l}\text { 1.Adolescence to adulthood } \\
\text { 2.Translucent hyperkeratotic papules, sometimes } \\
\text { umbilicated, on lateral aspects of palms and soles } \\
\text { 3. Autosomal Dominant }\end{array}$ & $\begin{array}{l}\text { 1.Hyperkeratosis and hypergranulosis } \\
\text { 2.Decreased number of fragmented elastic fibres }\end{array}$ & Unknown \\
\hline
\end{tabular}

PPK, Palmoplantar keratoderma; SLURP1, Secreted lymphocyte antigen 6 (LY6)/urokinase-type plasminogen activator receptor (uPAR)-related protein-1; KRT, Keratin;SERPIN7, serpin peptidase inhibitor, clade B (ovalbumin), member 7; DSG1, Desmoglein1; DSP, Desmoplakin;AAGAB, Alpha- and gamma-adaptin-binding protein p34;COL14A1, Collagen XIV

disease entity. Differential diagnosis of PPK is summarized in Table 2.

\section{Conclusion}

The identification of a novel homozygous nonsense variant in SLURP1, and a novel heterozygous nonsense variant in DSG1, as likely causes of PPK in the Pakistani families investigated alongside a review of previously reported variants adds to knowledge of the molecular causes of these conditions. Additionally, the data here provides important information regarding the nature, spectrum and molecular basis of PPK in Pakistan, enabling early clinical intervention, increased awareness regarding inherited disorders present in a community, and aiding diagnosis and counselling. 


\section{Additional file}

Additional file 1: Table S1. List of candidate pathogenic variants in SLURP1 gene previously reported in association with Mal de Meleda. Table S2. List of candidate pathogenic variants in DSG1 gene previously reported to be associated with Palmoplantar Keratoderma. (DOCX 66 kb)

\section{Abbreviations}

ARS-B: Arylsulfatase B; DSG1: Desmoglein 1; HGMD: Human gene mutation data base; MDM: Mal de Meleda; OMIM: Online Mendelian inheritance in man; PPK: Palmoplantar Keratoderma; SAM: Sinobronchial allergic mycosis; SERPIN7: Serpin Peptidase Inhibitor, Clade B (Ovalbumin), Member 7; SLURP1: Secreted ly6/plaur domain-containing 1 gene; WES: Whole Exome Sequencing

\section{Acknowledgements}

First and foremost, the authors would like to thank the affected individuals and their families for participation in this study. We also thank all of the clinicians and geneticists with whom we have collaborated for their input.

\section{Authors contributions}

Clinical data was collected and collated by AA, while, WA and GVH provided the assistance in genomic DNA extraction. AA, CP1 (Claire Prince), CP2 (Chloe Payne), GVH, AHC, ELB, JF performed genetic testing, analyzed and interpreted the patient data. AA, AG and GVH drafted the manuscript. Study was supervised by ELB, AHC, and AG. All authors reviewed, read and approved the manuscript.

\section{Authors information}

Not applicable

\section{Funding}

This study was partially supported by the Higher Education Commission (HEC) of Pakistan by awarding International Research Support Initiative Program (IRSIP) (Grant No: 1-8/HEC/HRD/2017/7949, PIN: IRSIP 37 BMS 39) to AA and RILD Wellcome Wolfson Centre (Level 4), Royal Devon and Exeter NHS Foundation Trust, UK. Exome/Sanger sequencing and analysis was carried out at RILD Wellcome Wolfson Center UK and was funded by HEC Pakistan and Wellcome Trust UK (to ELB).

\section{Availability of data and materials}

The patient's non-sensitive datasets used and/or analyzed during the current study are available from the corresponding author on reasonable request.

\section{Ethics approval and consent to participate}

The study was approved by the Ethical Review Boards Committee of International Islamic University Islamabad, Pakistan, and the study was carried out in accordance with the principles outlined in the Declaration of Helsinki (1964). Informed written consent was obtained for all participants, including minors ( $<16$ years of age) with parental consent, for the collection of blood samples with clinical evaluations and family histories performed by a dermatologist.

\section{Consent for publication}

Written informed consents were obtained for publication of clinical and genetic data from individuals $>18$ years, while consent for individuals $<18$ years of age were given by their parents or legal guardians.

\section{Competing interests}

WA is a member of the editorial board (Associate Editor) of BMC Medical Genetics. All other authors declare that they have no competing interests.

\section{Author details}

${ }^{1}$ Department of Biological Sciences, International Islamic University, $\mathrm{H}-10$, Islamabad 44000, Pakistan. ${ }^{2}$ College of Medicine and Health, RILD Wellcome Wolfson Centre, University of Exeter, Royal Devon \& Exeter NHS Foundation Trust, Barrack Road, Exeter EX2 5DW, UK. ${ }^{3}$ Department of Biochemistry, Faculty of Biological Sciences, Quaid-e-Azam University (QAU), Islamabad, Pakistan. ${ }^{4}$ Rajarshi Shahu College of Pharmacy, Malvihir Buldana, Maharashtra Post code 443001, India.
Received: 25 April 2019 Accepted: 2 August 2019

Published online: 23 August 2019

\section{References}

1. Patel S, Zirwas M, English JC. Acquired palmoplantar keratoderma. Am J Clin Dermatol. 2007:8(1):1-1.

2. Has C, Technau-Hafsi K. Palmoplantar keratodermas, clinical and genetic aspects. J Dtsch Dermatol Ges. 2016;149(2):3-142.

3. Guerra L, Castori M, Didona B, Castiglia D, Zambruno G. Hereditary palmoplantar keratodermas. Part I. non-syndromic palmoplantar keratodermas: classification, clinical and genetic features. J Eur Acad Dermatol Venereol. 2018;32(5):704-19.

4. Sakiyama T, Kubo A. Hereditary palmoplantar keratoderma "clinical and genetic differential diagnosis". J Dermatol. 2016;43(3):264-74.

5. Fatović-Ferencić S, Holubar K. The portrait and paper of a forgotten hero-Luca Stulli (1772-1828) and the mal de Meleda of yesteryear: a 175-year anniversary. J Invest Dermatol. 2001;116(1):198.

6. Bergqvist C, Kadara H, Hamie L, Nemer G, Safi R, Karouni M, Marrouche N, Abbas O, Hasbani DJ, Kibbi AG, Nassar D. SLURP-1 is mutated in mal de Meleda, a potential molecular signature for melanoma and a putative squamous lineage tumor suppressor gene. Int J Dermatol. 2018;57(2):162-70.

7. Itin PH, Fistarol SK. Palmoplantar keratodermas. Clin Dermatol. 2005;23(1):15-22.

8. Perez C, Khachemoune A. Mal de Meleda: a focused review. Am J Clin Dermatol. 2016:17(1):63-70.

9. Fischer J, Bouadjar B, Heilig R, Huber M, Lefèvre C, Jobard F, Macari F, BakijaKonsuo A, Ait-Belkacem F, Weissenbach J, Lathrop M. Mutations in the gene encoding SLURP-1 in mal de Meleda. Hum Mol Genet. 2001;10(8):875-80.

10. Tjiu JW, Lin PJ, Wu WH, Cheng YP, Chiu HC, Thong HY, Chiang BL, Yang WS, Jee SH. SLURP1 mutation-impaired T-cell activation in a family with mal de Meleda. Br J Dermatol. 2011;164(1):47-53.

11. Lyukmanova EN, Shulepko MA, Kudryavtsev D, Bychkov ML, Kulbatskii DS, Kasheverov IE, Astapova MV, Feofanov AV, Thomsen MS, Mikkelsen JD, Shenkarev ZO. Human secreted Ly-6/uPAR related protein-1 (SLURP-1) is a selective allosteric antagonist of a7 nicotinic acetylcholine receptor. PLoS One. 2016:11(2):0149733.

12. Rickman L, Šimrak D, Stevens HP, Hunt DM, King IA, Bryant SP, Eady RA, Leigh IM, Arnemann J, Magee Al, Kelsell DP. N-terminal deletion in a desmosomal cadherin causes the autosomal dominant skin disease striate palmoplantar keratoderma. Hum Mol Genet. 1999:8(6):971-6.

13. Milingou M, Wood P, Masouye I, McLean WH, Borradori L. Focal palmoplantar keratoderma caused by an autosomal dominant inherited mutation in the desmoglein 1 gene. Dermatol. 2006;212(2):117-22.

14. Keren H, Bergman R, Mizrachi M, Kashi Y, Sprecher E. Diffuse nonepidermolytic palmoplantar keratoderma caused by a recurrent nonsense mutation in DSG1. Arch Dermatol. 2005;141(5):625-8.

15. Samuelov L, Sarig O, Harmon RM, Rapaport D, Ishida-Yamamoto A, Isakov O, Koetsier JL, Gat A, Goldberg I, Bergman R, Spiegel R. Desmoglein 1 deficiency results in severe dermatitis, multiple allergies and metabolic wasting. Nat Genet. 2013;45(10):1244

16. Favre B, Plantard L, Aeschbach L, Brakch N, Christen-Zaech S, de Viragh PA Sergeant A, Huber M, Hohl D. SLURP1 is a late marker of epidermal differentiation and is absent in mal de Meleda. J Invest Dermatol. 2007; 127(2):301-8.

17. Arredondo J, Chernyavsky Al, Webber RJ, Grando SA. Biological effects of SLURP-1 on human keratinocytes. J Invest Dermatol. 2005;125(6):1236-41.

18. Grando SA, Pittelkow MR, Schallreuter KU. Adrenergic and cholinergic control in the biology of epidermis: physiological and clinical significance. J Invest Dermatol. 2006;126(9):1948-65.

19. Muslumanoglu MH, Saracoglu N, Cilingir O, et al. A novel mutation in the ARS (component B) gene encoding SLURP-1 in a Turkish family with mal de Meleda. Br J Dermatol. 2006:155(2):467-9.

20. Fischer J, Bouadjar B, Heilig R, Huber M, Lefèvre C, Jobard F, Macari F, BakijaKonsuo A, Ait-Belkacem F. Weissenbach J, Lathrop M. Mutations in the gene encoding SLURP-1 in mal de Meleda. Hum Mol Gene. 2001;10(8):875-80.

21. Taylor JA, Bondavalli D, Monif M, Yap LM, Winship I. Mal de Meleda in Indonesia: mutations in the SLURP1 gene appear to be ubiquitous. Australas J Dermatol. 2014:57(1):11-3.

22. Zhang J, Cheng R, Ni C, Liang J, Yao Z. First mal de Meleda report in Chinese mainland: two families with a recurrent homozygous missense mutation in SLURP-1. J Eur Acad Dermatol Venereol. 2015;30(5):871-3. 
23. Shah K, Nasir A, Shahzad S, Khan S, Ahmad W. A novel homozygous mutation disrupting the initiation codon in the SLURP1 gene underlies mal de Meleda in a consanguineous family. Clin Exp Dermatol. 2016;41(6):675-9.

24. Hammers CM, Stanley JR. Desmoglein-1, differentiation, and disease. J Clin Invest. 2013;123(4):1419-22.

25. Getsios S, Simpson CL, Kojima SI, Harmon R, Sheu LJ, Dusek RL, Cornwell M, Green KJ. Desmoglein 1-dependent suppression of EGFR signaling promotes epidermal differentiation and morphogenesis. J Cell Biol. 2009; 185(7):1243-58.

26. Lovgren ML, MCAleer MA, Irvine AD, Wilson NJ, Tavadia S, Schwartz ME, Cole C, Sandilands A, Smith FJD, Zamiri M. Mutations in desmoglein1 cause diverse inherited palmoplantar keratoderma phenotypes:implications for genetic screening. Br J Dermatol. 2017;176(5):1345-50.

27. Vodo D, OToole EA, Malchin N, Lahav A, Adir N, Saring O, Green KJ, FJD, Sprecher E. Striate palmoplantar kerato-derma resulting from a missense mutation in DSG1. Br J Dermatol 2018;179(3):755-757.

28. Hovorka O. E. Ehlers Mal de Meleda. Arch Dermatol Res. 1897:40:251-6.

29. Mitsuhashi Y, Hashimato I. Keratosis palmoplantaris Nagashima. Dermatol. 1989;179:231.

30. Kabashima K, Sakabe JI, Yamada Y, Tokura Y. "Nagashima-type" keratosis as a novel entity in the palmoplantar keratoderma category. Arch Dermatol 2008:144(3):375-379.

31. Kubo A, Shiohama A, Sasaki T, Nakabayashi K, Kawasaki H, Atsugi T, Sato S, Shimizu A, Mikami S, Tanizaki H, Uchiyama M. Mutations in SERPINB7, encoding a member of the serine protease inhibitor superfamily, cause Nagashima-type palmoplantar keratosis. Am J Hum Genet. 2013:93(5):945-56.

32. Dua-Awereh MB, Shimomura Y, Kraemer L, Wajid M, Christiano AM. Mutations in the desmoglein 1 gene in five Pakistani families with striate palmoplantar keratoderma. J Dermatol Sci. 2009;53(3):192-7.

\section{Publisher's Note}

Springer Nature remains neutral with regard to jurisdictional claims in published maps and institutional affiliations.

Ready to submit your research? Choose BMC and benefit from:

- fast, convenient online submission

- thorough peer review by experienced researchers in your field

- rapid publication on acceptance

- support for research data, including large and complex data types

- gold Open Access which fosters wider collaboration and increased citations

- maximum visibility for your research: over $100 \mathrm{M}$ website views per year

At $\mathrm{BMC}$, research is always in progress.

Learn more biomedcentral.com/submissions 